\title{
The Use of Indirectness Devices in Persian and English Argumentative Written Discourse: A Cross-Cultural Perspective
}

\author{
Ehsan Alijanian (Corresponding author) \\ Dept. of English Language, University of Isfahan, Isfahan, Iran \\ E-mail: ehsanalijanian@gmail.com \\ Hossein Vahid Dastjerdi \\ Dept. of English Language, University of Isfahan, Isfahan, Iran \\ E-mail: h_vahid@yahoo.com
}

Received: April 29, 2012 Accepted: May 14, 2012 Published: September 1, 2012

doi:10.5296/ijl.v4i3.1733ＵRL: http://dx.doi.org/10.5296/ijl.v4i3.1733

\begin{abstract}
Speakers of different languages have conventions that are not necessarily shared outside of a particular tradition (Kaplan, 1990). Accordingly, written discourse is dependent on the value systems and cultural beliefs and practices of a particular community (Poole, 1991). Indirectness is considered a universal discoursal strategy but the extent to which it is applied varies from culture to culture. The present study is an attempt to compare the use of six indirectness devices in Persian and English argumentative essays. Thesis statement, rhetorical question, irony, hedges, the passive voice, and conditional tense were the items investigated. The findings indicate that Persian writers made significantly greater use of devices such as thesis statement, irony, hedges, and the passive voice than their English counterparts. The distinction between the two traditions may cause breakdowns in cross-cultural communication of the two groups. Likewise, teachers and students need to be familiar with these norms of discourse organization and thinking patterns.
\end{abstract}

Keywords: Written discourse, Cultural beliefs, Indirectness, Discourse organization 


\section{Introduction}

The publication of Kaplan`s 1966 influential article 'Cultural Thought Patterns in Intercultural Education', gave birth to the notion now known as contrastive rhetoric. Contrastive rhetoric in part derived from Whorfian ideas of the associations among language, culture, and thought, is a hypothesis asserting that the logic manifested through the discourse of written text is culture-specific; in other words, it proposes that people who speak different languages will organize the same reality in different ways (Kaplan, 1990). Kaplan further stated that speakers of different languages have different cultural thinking patterns that are indicative of their written discourse (Kaplan, 1990). According to this theory, speakers of Asian languages do not use the same type of discourse organization that native English speakers use; native English writers are inclined to adopt a direct and to-the-point approach, whereas Asian writers are inclined to adopt an indirect, talking around- the-point pattern of organization (Kaplan, 1990).

In the same line, Gee (1990) points out that specific social communities have particular discourse practices and styles which are expressive of their different worldviews, values, and traditions. According to Swales (1990), a discourse community cannot be defined explicitly and often it includes extensive notions, such as a series of common public goals and mechanisms of interchange among its affiliates. Written discourse in different languages and cultural communities is often conventionalized and these conventions are not necessarily shared in rhetorical paradigms outside a particular culture (Kachru, 1992).

Indirectness in interpersonal communication is present in many cultures around the world; however, it appears in smaller frequencies in Western composition. It can consist of a circular discoursal style in which the communicative intention is achieved strategically (by using such devices as irony, rhetorical question, passive voice, etc) or expressed only after a number of remotely-related points have been given (Tran, 2007). The circuitous approach to a proposition is deployed when there is a need for speaker/writer to dodge or delay that particular delicate point in conversation or composition (Scollon, 1997). Also the delayed theme or erratic development in writing is intended to respect the reader`s comprehension (Fox, 1994). Indirectness is thus mostly related to politeness (Felix-Brasdefer, 2004). It can be mentioned that this cross-cultural communicative strategy is to remove the writer from (1) liability for the truthfulness of the information provided (Afifi \& reichert, 1996) or (2) any potential conflicts with the reader arising from proposition (Chew, 1992) and thus ensure either the author`s self-protection or solidarity/harmony with the reader (Rymes, 1995). In addition this politeness strategy is used to avoid face-threatening acts (Wu and Rubin, 2000). Goffman (1967) was the first scholar who in his investigations about ritual constraints in social interactions emphasized the role of presentation of self and presentation of others in constructing the social face. Face is thus the public self image or more specifically the 'emotional and social sense of self that every person has and expects everyone else to recognize’ (Yule, 1996, p. 134).

From the communicative standpoint, Oliver (1971) speculates that the value system of each specific tradition affects indirection in a process he calls 'cultural orientation of 
communication' (P. 129). Further, Hall and Ames (1995) assert that in 'polychronic' cultures which behold the different events of the world as occurring simultaneously and thus of equal importance digressive writing patterns are evident; whereas, in the American 'monochronic' culture the linear topic progression is witnessed since in this tradition everything is expected one after another hierarchically (P. 61).

Usually in English written discourse, it is necessary to have straightforward expression of the primary ideas related to the text's thesis and clear description of the writer's opinion (Swales, 1990). However, indirectness markers need to be used properly and vagueness should be abstained because explicitness, accuracy, precision, and rational support are the primary objectives that the writer tries to achieve (Swales, 1990). According to Myers (2004) hedges, denials, impersonal constructions, and other markers of indirectness are vital in the sense that they are strategies for the writer to maintain politeness in written academic discourse especially when ideas are advanced and promoted. It is also envisaged that English texts exhibit a high degree of structure, text progression, and clarity (Liu, 1996).

Plenty of research has been conducted on indirectness in various languages and cultures. The disciplinary literature has revealed indirectness as a discoursal tendency more typical to non-Western cultures although it also exists to a degree in Western culture (Wu \& Rubin, 2000). A number of studies have examined implicitness and explicitness in languages such as Korean, Japanese, and Chinese. According to Hinds (1990), a piece of writing is built around a theme, which embodies the rhetorical purpose of an essay with an intention of causing the reader to think about an issue and thus direct reasoning, discussion, and persuasion are not common in Chinese, Korean, and Japanese written discourse.

ScolIon and Scollon (1995) mention that in Chinese essay writing, politeness strategies play a key role in progression of the written text and the exchange of information between the writer and the reader is based on the politeness of facework and mutual harmony. According to Chu (2006), a determining feature of Chinese discourse is putting the burden of interpreting meaning on the reader rather than transmitting meaning in plain words. In such a tradition shared background awareness is the primary means by which the reader decodes the writer`s meaning and assumption (Hinds, 1990). In the same manner, in Korean discourse, indirectness and uncertainty are called for within the frameworks of Confucian ethics to secure human rapport. Unequivocal explication and persuasion are infrequently exercised (Chew, 1992). Scollon and Scollon (1995) attribute indirectness to collectivist values in Chinese culture. According to them, Chinese cultural concepts are different to individualistic cultural values in the West; In Chinese community, people are encouraged to show respect and keep conformity in the group; they tend to beat around the bush and do not state the main idea directly.

According to Hinds (1990) in Japanese written text communication at the level of minds is more important to communication at the level of words. Thus uncertainty, implicitness, and obscurity are tremendously appreciated in such an atmosphere. In such a context, indirectness devices are used abundantly to implicate that information is not inferable from any clear source but it is present as an independent actuality (Spees, 1994). In this culture, indirectness 
devices can be used to hedge propositions, establish solidarity between the speaker/writer and hearer/reader, show that information exists as an independent fact not attributable to any discernible source, and, thus, depersonalize the speaker's/ writer's position (Swales, 1990). Indirectness is exercised to create harmony between the interlocutors, limit statements, and avoid responsibility for ideas (Hinds, 1990).

Implicit discourse demonstrates the writer's constructive purpose as well as cooperation and will bring about solidarity and social harmony (Channel, 1994). Moreover, the writer by resorting to such a strategy can do away with the responsibility for accuracy of the information or even can save the readers from the impact of direct expression which in turn will cause avoidance of potential conflict (Wu \& Rubin, 2000). Young (1994) believes that indirectness is rooted in 'strictly hierarchical societies' in which every person is surrounded in an interwoven system of relations with other members of the society and preserving social harmony is a prerequisite for survival in such a community (P. 9).

Through schooling and education learners are made familiar to the social norms and discourse traditions (Scollon, 1997). For many outsiders, picking up this new identity is in contrast to their primary socialization and internalization of these social values (Gee, 1990). This disparity and distinction in ways to get the message across may affect cross-cultural communication and acceptability of non-Western writers (kennedy, 1998). This circular attitude to the topic can give rise to communication breakdown, hold up the audience, and spoil interaction as readers from different cultures and thought patterns have diverse assumptions of the ways to express the message (Rymes, 1996). In non-Western prose, grasping these meaning making systems is the responsibility of the reader while in Western writing style it is the responsibility of the writer to make meaning clear and this results in a significant incongruity (Hinds, 1990). The audience who is not familiar to these issues may feel bewildered by this unacquainted topic advancement and by facing some seemingly loose ideas in the text (Sew, 1997).

\section{The Study}

Brown and Levinson (1987) introduce a comprehensive definition of indirectness as a set of politeness strategies with the objective of reducing imposition on the hearer and/or bringing about solidarity between the speaker and the hearer. These markers are divided into three major categories:

(A) Rhetorical strategies and markers: items in this category have a persuasive objective. They include rhetorical questions, tag questions, disclaimers and denials, vagueness and ambiguity markers, repetition, and irony (Brown \& Levinson, 1987).

(B) Lexical and referential markers: Tools of this category rely on their meaning as well as relationships to indirectly approach/present a claim. They contain hedges and hedging devices, point of view distancing, downtoners, dimunitives, discourse particles, demonstratives, indefinite pronouns and determiners, and some understatement markers (Brown \& Levinson, 1987). 
(C) Syntactic markers and structures: They are indirectness devices manifested in the sentence structures including passive voice, nominalization, and conditional tenses (Brown \& Levinson, 1987).

The present study tries to examine the use of indirectness devices in argumentative essays written by Persian and English authors. Due to our limitations only six items were selected for investigation. Thesis statement, rhetorical question, irony, hedges (lexical and possibility), passive voice, and conditional structures were among the items that were analyzed. Each of these devices will be discussed in section three.

Argumentative essay was chosen for our investigation since in this mode of discourse the author takes a stand on a debatable issue, persuades others to see things in his/her way, and more importantly, encourages them to take actions (Hirose, 2003). Therefore, it can better shed light on the direct or indirect approach that writers take in getting their point across.

\subsection{Material}

Thirty Persian and thirty English sample essays were analyzed with regards to the use of indirectness devices. The English compositions were chosen from the preparatory TOEFL textbook 'How to prepare for the TOEFL essays' (Lougheed, 2006). Persian essays were gathered by asking 30 graduate students of Persian Language and Literature (minimum degree of BA in the mentioned discipline) to compose 30 argumentative essays. The essays were of middle-sized length (around 250 words).

\section{Data Analysis and Results}

In order to find out if there was a significant difference between Persian and English essays in terms of having a thesis sentence in the introduction, the number of essays having this item was counted in Persian and English texts. Chi square was applied to see if the frequencies were starkly different. For the five remaining features, the number of words in every essay and the frequency of that specific indirectness device were counted. In order to ascertain the percentage rate of occurrence of every tool, at first 1 was divided by the number of words in that essay (e.g., $1 / 200=0.5 \%$ ) and then the number of times that device was used was multiplied in the result of the division (e.g., $0.5 \% * 3=1.5 \%$ ). This procedure was performed for each of these tools and every essay separately. Since the data was not normally distributed, Mann-Whitney U test was used to check out the significance of the differences between Persian and English essays. The results are tabulated as follows:

Table 1. Thesis statement in the introduction of Persian and English essays

\begin{tabular}{|c|c|c|c|}
\hline Location of the Thesis Statement & $\frac{\text { Persian texts }}{\text { Number } \% \text { of }}$ & 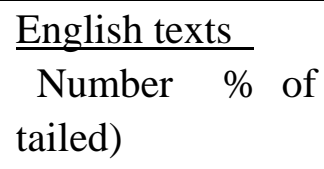 & $\begin{array}{l}\text { p-value } \\
\text { (two }\end{array}$ \\
\hline Direct approach & 63 & 93 & $.00 *$ \\
\hline
\end{tabular}


Table 2. Indirectness devices in Persian and English essays

\begin{tabular}{|c|l|l|l|}
\hline Discourse device & Persian texts & $\begin{array}{l}\text { English } \\
\text { texts }\end{array}$ & P value \\
\hline Rhetorical strategies and markers & & & \\
\hline Rhetorical question & .17 & .09 & $.00^{*}$ \\
\hline Irony & .10 & .97 & .07 \\
\hline $\begin{array}{c}\text { ((2) Lexical and referential markers } \\
\text { Hedges }\end{array}$ & & & \\
\hline Lexical & .14 & .11 & $.00^{*}$ \\
\hline Quality & .13 & .11 & $.00^{*}$ \\
\hline (3) Syntactic markers & & & \\
\hline Passive & .25 & .12 & $.00^{*}$ \\
\hline Conditional & .09 & .08 & .06 \\
\hline
\end{tabular}

The results of data analysis as shown in the above tables indicate that Persian and English essays were significantly different in terms of having some indirectness devices such as thesis statement, rhetorical questions, hedges, and the passive voice, but no significant difference was found between the essays regarding the use of irony and conditional sentences. The results are discussed below:

\subsection{Thesis Statement}

Based on Kaplan`s idea of direct and to the point organization versus indirect, talking around the point organization, direct approach was defined as having a thesis statement clearly stated in the introduction (Kaplan, 1990). The writer`s explicit statement in agreement or disagreement with the topic was considered as the thesis statement. The results indicate that English writers are significantly more direct than Persian writers in terms of stating a thesis statement in the introduction part. Scollon (1997) believes that indirectness is linked to cultural concepts and collectivist values that may differ in Western and Eastern cultures and these values impact the way people communicate with one another. It can be hypothesized that by not mentioning the thesis sentence early on, Persian writers may seek to show respect and maintain harmony in the group. Persian writers seem to have the tendency to delay expressing the main idea or even to talk around the topic without stating the main idea directly. In written communication, this may prevent Persian writers from employing a thesis sentence at the begining of writing. Although English writers take a stand on an issue in the introduction part of their essays, Persian authors prefer not to state the main idea very quickly. Maintaining Persian readers`interest can be another function of not mentioning the thesis statement in the introduction. Persian readers may lose interest if the main idea is stated clearly at the very beginning of the essay.

\subsection{Rhetorical Question}

Rhetorical question is a common indirectness device used in many contexts; It is a device for stating indirectness and uncertainty because it has a proposition that although plays the role 
of statement, allows the writer to avert potential disagreement (Brown \& Levinson, 1987). Wong (1990) believes that through using rhetorical questions, writers can hint about the purpose of their texts and state their idea without a direct expression. Through using these questions Persian writers may have planned to refrain from imposition on the readers while involving them in the text. In Persian texts markedly more rhetorical questions were found.

\subsection{Irony}

According to Brown and Levinson (1987) irony as indirectness marker can give clues to the intended meaning without directly stating what the intended meaning is. Writers can refute potential objections, avoid a threat to their own and their readers' face, and avert confrontation with their audience through using irony (Leech, 2006). Persian writers made use of irony more frequently than their English peers although the difference was not significant.

\subsection{Hedges}

a) Lexical: (at) about, in a way, kind of, maybe, more or less, most, something like, sort of

b) Possibility: by (some/any) chance, hopefully, perhaps, possibly, in case (of), (if) you/we know/understand (what <pron> mean (s))

Hedges come in various categories but because of our limitations only the two taxonomies of lexical and possibility were analyzed in this study. Brown and Levinson (1987) define hedges as a way to explain and limit the force of claims, the certainty of a proposition and the writer`s commitment in stating a message completely. According to Leech (2006), hedges can have the role of decreasing the enforcement of ideas which can cause problems to the reader/hearer. They can be used to express personal point of view and make the situation smooth for offering a claim. Hedges are effective and flexible discourse markers to indicate doubt, hesitation, politeness and indirectness (Biber, 2004). Swales (1990) believes that the number and kind of hedges used in different communities are conventionalized and relies on the norms of a particular culture. Since there were no authorized sources about hedges in Persian, we had to pick out actual equivalent words while working on Persian texts. The significantly different number of hedges used in Persian and English texts can be an indicator of different discourse conventions in the two groups.

\subsection{Passive Voice}

Brown and Levinson (1987) count the passive voice as an indirectness discourse marker that has the function of avoiding direct reference to the speaker or the hearer and precluding enforcement of a possible threat to the speaker`s/hearer`s face. By using the passive voice, the authors can lower the force of the verb drastically and make it difficult for that claim to be openly rejected (Atkinson, 1994). Politeness and deference can also be achieved by making passive sentences since these claims are less certain (Master, 2002). In this study in Persian texts more passive sentences was discovered and the difference was significant between the two traditions. 


\subsection{Conditional Tenses}

According to Brown and Levinson (1987), hypothetical constructions often result in indirectness when the speaker mitigates the illocutionary force and expresses claims and ideas as if they would be denied or refused. Through using conditional tense, the writer can prevent a threat to his or her face and even this device can be employed as a solidarity strategy in case that everyone can agree with the claim (Myers, 2004). Even the author can bring about agreement of the reader in making claims that are risky through using this device; having a smaller risk of negatability and contributing to the indeterminacy of the structure that follows can be outlined amongst other merits of this indirectness device (Fox, 1994). In our study, more conditional tenses were encountered in Persian texts although this difference was not significant.

\section{Concluding Remarks}

All in all, it can be mentioned that in Iranian culture, writing is a way to build a relationship. This is a determining objective in the way an individual associates and interacts with other members of a community. Interlocutors are cautious in deciding on others aims and statements in relation to their own. This is a key factor in indirect expressions and concerns for other peoples` face and priority for partnership and feeling. Controversy and dispute are seen as a threat and a direct challenge that cause an individual to lose face. This can be a deciding factor in the indirectness that encompasses the Persian culture with the major objective of arriving at consensus and reciprocal harmony.

On the other hand, in English, writing is considered as a medium to accomplish a task (i.e., to state an argument or express a point). The writer has the commitment to attend to clarity, be specific and explicit. English authors prefer a direct approach and use the most concise and efficient way to express their points. The emphasis is on letting readers accurately receive information so we can witness a strict process to arrange the logic in a way that everything is connected one by one and is closely linked to the position the author takes at the very beginning of the writing.

Generally speaking, indirectness in Persian writing is considered an artistic style with the aim of achieving respect and indicating harmony in human communication. Persian readers are more patient in reading compositions; they are expected to realize the connotation of a text and work hard. Even it can be suggested that stating the points too clearly is disrespecting the readers; the writer is expected to give room to his interlocutors for interpretation. Traditionally, Persian literature is dynamic and the ideas of reflective thinking, open mindedness, making meaning, and quest for inquisition and exploration are what Persian writers are perusing.

To summarize, use of indirectness discourse markers is a facet where there are possible inconsistencies across languages; there are preferences for specific discourse devices in different languages. Therefore, it seems necessary to become familiar with potential problems in writing specific to each language and try to control these issues. In the same vein, 
cognizance and consciousness should be practiced in attributing distinct characteristics to people with a particular culture or language background.

Discourse organization which is part of culture is both implicit and explicit in the spreading of several forms such as teaching. From a pedagogical point of view, teachers should become aware of these discourse patterns in diverse languages and subsequently inform their students of such variations in the ways of thinking and standards of discourse organization in writing. For example, the L2 teachers and students can discuss the similarities and differences between the two traditions. Asking students to compare L1 and L2 textbooks with regards to the use of indirectness devices can be a strategy to familiarize students with different styles of writing. It is advisable for foreign language learners to see how English speakers enact their worldviews, rhetorical patterns, and values in mind. L2 teachers can steadily change their students ' perceptions on how to write in English by helping them grasp the norms of rhetorical conventions, standards, and expectations in the target language.

Moreover, it seems essential to come to the understanding that there is no entire superior or inferior approach to writing, whether written in a direct or indirect way. Usually norms of writing are indicative of shared values tied up to cultures themselves (Grabe, 2001). A multitude of pragmatic norms and values should be made explicit and L2 learners will benefit from raised awareness of these issues particularly when these conventions are in contrast to their native language.

Finally, it is important to mention that use of indirectness discourse markers in English and Persian is not the only pattern that differs in the two traditions. The existence of collectivist values in Persian culture may also explicate issues such as the use of more historical references such as proverbs, famous quotes, and known stories in Persian texts. Also the easygoing approach of Persian writers in giving citations (knowledge belongs to all) can be another line of inquiry for future research in the field.

\section{References}

Afifi, A., \& Reichert, T. (1996). Understanding the role of uncertainty in jealousy experience and expression. Communication Reports, 9(2), 94-103.

Atkinson, D. (1994). Communicative language teaching in the 1990s: A consumer's perspective. TESOL France, 2(1), 101-111.

Biber, D. (2004). Historical patterns for the grammatical marking of stance: A cross-register comparison. Journal of Historical Pragmatics, 5, 107-135. http://dx.doi.org/10.1075/jhp.5.1.06bib

Brown, P., \& Levinson, S. (1987). Politeness (2nd ed.). Cambridge: Cambridge University Press.

Channel, J. (1994). Vague language. Oxford: Oxford University Press.

Chew, P. (1992). Teaching indirectness. Guidelines, 14(1), 14-22. 
Cho, J. H. (1999). A study of contrastive rhetoric between East Asian and North American cultures as demonstrated through student expository essays from Korea and the United States. Unpublished doctoral dissertation, Bowling Green State University.

Félix-Brasdefer, J. (2004). Interlanguage refusals: linguistic politeness and length of residence in the target community. Language Learning, 54(4), 587-653. http://dx.doi.org/10.1111/j.1467-9922.2004.00281.x

Ford, S. (2004). Contingency and units in interaction. Discourse studies, 6(1), 27-52. http://dx.doi.org/10.1177/1461445604039438

Fox., H. (1994). Listening to the world: cultural iussues in academic writing. Urbana, IL: NCTE.

Gee, P. (1990). Social linguistics and literacies. Bristol, PA: Falmer.

Goffman, E. (1967). Interaction ritual: Essays on face-to-face behavior. New York: Doubleday.

Grabe, W. (2001). Notes toward a theory of second language writing. In T. Silva., \& P. K. Mastuda (Eds.), On second language writing (pp. 39-58). Mahwah, NJ: Erlbaum.

Hall, D. L., \& Ames, R. T. (1995). Anticipating China: thinking through the narratives of Chinese and Western cultures. Albany, NY: State University of New York Press.

Hinds, J. (1990). Inductive, deductive, quasi-inductive; expository writing in Japanese, Korean, Chinese, and Thai. In U. Connor., \& A. M. Johns (Eds.), Coherence in writing: research and pedagogical perspectives (pp. 87-109). Alexandria, VA: TESOL.

Hirose, K. (2003). Comparing L1 and L2 organizational patterns in the argumentative writing of Japanese EFL students. Journal of Second Language Writing, 12, 181-209. http://dx.doi.org/10.1016/S1060-3743(03)00015-8

Kachru, Y. (1992). World Englishes: approaches, issues and resources. Language Teaching, 25(1), 1-14. http://dx.doi.org/10.1017/S0261444800006583

Kaplan, R. (1966). Cultural thought patterns in intercultural education. Language Learning, 16, 1-20. http://dx.doi.org/10.1111/j.1467-1770.1966.tb00804.x

Kaplan, R. (1990). Writing in a multilingual/multicultural context: what's contrastive about contrastive rhetoric? The Writing Instructor, 10, 7-18.

Kennedy, G. A. (1998). Comparative rhetoric: An historical and cross-cultural introduction. New York/Oxford: Oxford University Press.

Leech, G. (2006), Politeness: Is there an East-West divide. Journal of Politeness Research, 3.2, 167-206. http://dx.doi.org/10.1515/PR.2007.009.

Liu, Y. (1996). To capture the essence of Chinese rhetoric: An anatomy of a paradigm in comparative rhetoric. Rhetoric Review, 14(2), 318-335. http://dx.doi.org/10.1080/07350199609389068 


\section{Macrothink}

International Journal of Linguistics

ISSN 1948-5425

2012, Vol. 4, No. 3

Lougheed, L. (2006). How to prepare for the TOEFL essays: Test of English as a foreign language. Barron`s educational series, Inc.

Master, P. (2002). Information structure and article pedagogy. System, 30, 331-348. http://dx.doi.org/10.1016/S0346-251X(02)00018-0

Myers, G. (2004). Matters of opinion: talking about public issues. Public Opinion Quarterly, 70(3), 409-412.

Oliver, R. (1971). Communication and culture in ancient India and China. New York: Syracuse University Press.

Poole, D. (1991). Discourse analysis in ethnographic research. Annual Review of Applied Linguistics, 11, 42-56. http://dx.doi.org/10.1017/S026719050000194X

Rymes, B. (1995). African American English: An interview with Marcyliena Morgan. Issues in Applied Linguistics, 6(1), 85-98.

Scollon, R. (1997). Contrastive rhetoric, contrastive poetics, or perhaps something else? TESOL Quarterly, 31(2), 352-357. http://dx.doi.org/10.2307/3588051

Scollon, R., \& Scollon. S. W., (1995). Intercultural communication. Oxford: Blackwell.

Sew, J. W. (1997). Power pragmatics in Asian languages. Language Sciences, 19(4), 357-367. http://dx.doi.org/10.1016/S0388-0001(97)00001-6

Spees, H. (1994). A cross-cultural study of indirectness. Issues in Applied Linguistics, 5(2), 231-253.

Swales, J. (1990). Genre analysis. Cambridge: Cambridge University Press.

Tran, T. (2007). Indirectness in Vietnamese newspaper commentaries: A pilot study. Unpublished doctoral dissertation, Bowling Green State University.

Wong, H. (1990). The use of rhetorical questions in written argumentative discourse. In L. Bouton, \& Y. Kachru (Eds.), Pragmatics and language learning (Vol. 1, pp. 187-208). Urbana-Champaign: University of Illinois.

Wu, S., \& Rubin, D. L. (2000). Evaluating the impact of collectivism and individualism on argumentative writing by Chinese and North American college students. Research in the Teaching of English, 35(2), 148-178.

Young, W. L. (1994). Crosstalk and culture in Sino-American communication. Cambridge/New York: Cambridge University Press.

Yule, G. (1996). The study of language (2nd ed.). Cambridge: Cambridge University Press. 